\title{
Infrared and Raman spectroscopic characterization of the silicate mineral olmiite $\mathrm{CaMn}^{2+}\left[\mathrm{SiO}_{3}(\mathrm{OH})\right](\mathrm{OH})$ - implications for the molecular
} structure

\author{
Ray L. Frost ${ }^{\mathrm{a}, *}$, Ricardo Scholz ${ }^{\mathrm{b}}$, Andrés López $^{\mathrm{a}}$, Yunfei Xi ${ }^{\mathrm{a}}$, Amanda Granja ${ }^{\mathrm{b}}$, Željka Žigovečki Gobac ${ }^{\mathrm{c}}$, \\ Rosa Malena Fernandes Lima ${ }^{\mathrm{d}}$

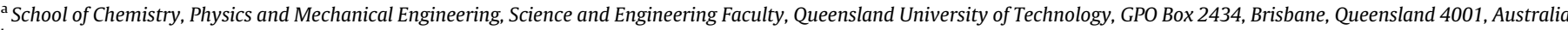 \\ ${ }^{\mathrm{b}}$ Geology Department, School of Mines, Federal University of Ouro Preto, Campus Morro do Cruzeiro, Ouro Preto, MG 35,400-00, Brazil \\ c Institute of Mineralogy and Petrography, Department of Geology, Faculty of Science, University of Zagreb, Horvatovac 95, 10000 Zagreb, Croatia \\ ${ }^{d}$ Mining Engineering Department, School of Mines, Federal University of Ouro Preto, Campus Morro do Cruzeiro, Ouro Preto, MG 35,400-00, Brazil
}

\section{H I G H L I G H T S}

- We have studied the structure of the mineral olmiite $\mathrm{CaMn}\left[\mathrm{SiO}_{3}(\mathrm{OH})\right](\mathrm{OH})$.

- It forms a series with its calcium analogue poldervaartite $\mathrm{CaCa}\left[\mathrm{SiO}_{3}(\mathrm{OH})\right](\mathrm{OH})$.

- We used scanning electron microscopy, thermogravimetric analysis, Raman and infrared spectroscopy.

- Thermogravimetric analysis proves the mineral decomposes at $502{ }^{\circ} \mathrm{C}$ with a mass loss of $8.8 \%$.

- Vibrational spectroscopy enables a detailed assessment of the molecular structure of olmiite.

\section{A R T I C L E I N F O}

\section{Article history:}

Received 3 July 2013

Received in revised form 18 August 2013

Accepted 19 August 2013

Available online 28 August 2013

\section{Keywords:}

Olmiite

Phosphate

Raman spectroscopy

Infrared spectroscopy

\begin{abstract}
A B S T R A C T
We have studied the mineral olmiite $\left.\mathrm{CaMn}_{\mathrm{SiO}}(\mathrm{OH})\right](\mathrm{OH})$ which forms a series with its calcium analogue poldervaartite $\mathrm{CaCa}\left[\mathrm{SiO}_{3}(\mathrm{OH})\right](\mathrm{OH})$ using a range of techniques including scanning electron microscopy, thermogravimetric analysis, Raman and infrared spectroscopy. Chemical analysis shows the mineral is pure and contains only calcium and manganese in the formula. Thermogravimetric analysis proves the mineral decomposes at $502{ }^{\circ} \mathrm{C}$ with a mass loss of $8.8 \%$ compared with the theoretical mass loss of $8.737 \%$. A strong Raman band at $853 \mathrm{~cm}^{-1}$ is assigned to the $\mathrm{SiO}$ stretching vibration of the $\mathrm{SiO}_{3}(\mathrm{OH})$ units. Two Raman bands at 914 and $953 \mathrm{~cm}^{-1}$ are attributed to the antisymmetric vibrations. Two intense Raman bands observed at 3511 and $3550 \mathrm{~cm}^{-1}$ are assigned to the $\mathrm{OH}$ stretching vibration of the $\mathrm{SiO}_{3}(\mathrm{OH})$ units. The observation of multiple $\mathrm{OH}$ bands supports the concept of the non-equivalence of the $\mathrm{OH}$ units. Vibrational spectroscopy enables a detailed assessment of the molecular structure of olmiite.
\end{abstract}

(c) 2013 Elsevier B.V. All rights reserved.

\section{Introduction}

The mineral olmiite, ideally $\mathrm{CaMn}\left[\mathrm{SiO}_{3}(\mathrm{OH})\right](\mathrm{OH})$, forms a series with poldervaartite, it is $\mathrm{Ca}$ analogue $-\mathrm{CaCa}\left[\mathrm{SiO}_{3}(\mathrm{OH})\right](\mathrm{OH})$ $[1,2]$. This mineral was first found in South Africa at the N'Chwaning II mine of the Kalahari manganese fields and occurs as a product of hydrothermal alteration of primary sedimentary and lowgrade metamorphic ores in a temperature range from $250{ }^{\circ} \mathrm{C}$ to $400{ }^{\circ} \mathrm{C}$. Usually olmiite occurs in associated with celestine, bultfonteinite, poldervaartite, sturmanite and hematite [1,2].

Olmiite crystallizes in the orthorhombic crystal system, with unit cell parameters $a=9.243(3), b=9.076(9), c=10.342(9) \AA$. $V=868(1) \AA^{3}[1,2]$. The atomic arrangement of olmiite is similar

\footnotetext{
* Corresponding author. Tel.: +61 73138 2407; fax: +61 731381804 .

E-mail address: r.frost@qut.edu.au (R.L. Frost).
}

to that of poldervaartite. Variations in bond distances and angles are related to the pronounced difference in the Mn content. The structure of both poldervaartite and olmiite can be schematically described, for convenience, as a sequence along [010] of alternating layers containing $\mathrm{M} 2+\mathrm{Si}$ and $\mathrm{M} 1$ polyhedra, respectively. Nonetheless, the strong three-dimensional linkage among the polyhedral units results in a rather isotropic framework, as pointed out by Dai $[1,2]$. Olmiite consists of isolated $\mathrm{SiO}_{3}(\mathrm{OH})$ tetrahedra continuously connected along the [100] direction to two $\mathrm{M}_{2} \mathrm{O}_{7}$ polyhedra by sharing edges. The M2-Si chains are linked together by corner sharing to form waved sheets parallel to (010) Alternating sheets are linked together by M1 octahedra and hydrogen bonds, resulting in a strongly bonded polyhedral network $[1,2]$.

The combination of scanning electron microscopy and vibrational spectroscopy has proven most useful for the study of the chemistry and molecular structure of minerals, In this work we 
have studied the mineral olmiite $\left.\mathrm{CaMn}_{\mathrm{SiO}}(\mathrm{OH})\right](\mathrm{OH})$ using a combination of techniques.

\section{Experimental}

\subsection{Samples description and preparation}

The olmiite sample studied in this work was obtained from the collection of the Geology Department of the Federal University of Ouro Preto, Minas Gerais, Brazil, with sample code SAB-098. The sample is from the type locality in $\mathrm{N}^{\prime}$ Chwaning II mine of the Kalahari manganese fields, South Africa. The mineral occurs in association with calcite and manganese oxides not determinate. The sample was gently crushed and the associated minerals were removed under a stereomicroscope Leica MZ4. Scanning electron microscopy (SEM) was applied to support the chemical characterization.

\subsection{Scanning electron microscopy (SEM)}

Experiments and analyses involving electron microscopy were performed in the Center of Microscopy of the Universidade Federal de Minas Gerais, Belo Horizonte, Minas Gerais, Brazil (http:// www.microscopia.ufmg.br).

Olmiite crystal aggregate was coated with a $5 \mathrm{~nm}$ layer of evaporated Au. Secondary Electron and Backscattering Electron images were obtained using a JEOL JSM-6360LV equipment. Qualitative and semi-quantitative chemical analyses in the EDS mode were performed with a ThermoNORAN spectrometer model Quest and was applied to support the mineral characterization.

\section{Electron microprobe analysis (EMP)}

Chemical characterization of olmiite was carried via EMP. One single crystal was selected and prepared in epoxy resin. The single crystal was analyzed with the performance of ten spots. The chemical analysis was carried out with a Jeol JXA8900R spectrometer from the Physics Department of the Federal University of Minas Gerais, Belo Horizonte. For each selected element, we used the following standards: Ca - anortite, $\mathrm{Si}$ - quartz, $\mathrm{Mg}$ - MgO, Fe - siderite and $\mathrm{Mn}$ - rhodonite. $\mathrm{H}_{2} \mathrm{O}$ was calculated by stoichiometry. The epoxy embedded olmiite sample was coated with a thin layer of evaporated carbon. The electron probe microanalysis in the WDS (wavelength dispersive spectrometer) mode was obtained at $15 \mathrm{kV}$ accelerating voltage and beam current of $10 \mathrm{nA}$. Chemical formula was calculated on the basis of five oxygen atoms (O). ZAF correction was applied with support of the JEOL software $\mathrm{XM}-97312$. The error in measurements is considered $\pm 2 \mathrm{wt} \%$.

\subsection{Thermogravimetric analysis - TG/DTG}

TG/DTG analysis of the olmiite were obtained by using TA Instruments Inc. Q50 high-resolution TGA operating at a $10^{\circ} \mathrm{C} /$ min ramp with data sample interval of $0.50 \mathrm{~s} / \mathrm{pt}$ from room temperature to $1000{ }^{\circ} \mathrm{C}$ in a high-purity flowing nitrogen atmosphere $\left(100 \mathrm{~cm}^{3} / \mathrm{min}\right)$. A total mass of $40.00 \mathrm{mg}$ of finely ground samples were heated in an open platinum crucible.

\subsection{Raman microprobe spectroscopy}

Crystals of olmiite were placed on a polished metal surface on the stage of an Olympus BHSM microscope, which is equipped with $10 \times, 20 \times$, and $50 \times$ objectives. The microscope is part of a Renishaw 1000 Raman microscope system, which also includes a monochromator, a filter system and a CCD detector (1024 pixels).
The Raman spectra were excited by a Spectra-Physics model 127 He-Ne laser producing highly polarized light at $633 \mathrm{~nm}$ and collected at a nominal resolution of $2 \mathrm{~cm}^{-1}$ and a precision of $\pm 1 \mathrm{~cm}^{-1}$ in the range between 200 and $4000 \mathrm{~cm}^{-1}$. Repeated acquisitions on the crystals using the highest magnification $(50 \times)$ were accumulated to improve the signal to noise ratio of the spectra. Raman Spectra were calibrated using the $520.5 \mathrm{~cm}^{-1}$ line of a silicon wafer. The Raman spectrum of at least 10 crystals was collected to ensure the consistency of the spectra.

\subsection{Infrared spectroscopy}

Infrared spectra were obtained using a Nicolet Nexus 870 FTIR spectrometer with a smart endurance single bounce diamond ATR cell. Spectra over the $4000-525 \mathrm{~cm}^{-1}$ range were obtained by the co-addition of 128 scans with a resolution of $4 \mathrm{~cm}^{-1}$ and a mirror velocity of $0.6329 \mathrm{~cm} / \mathrm{s}$. Spectra were co-added to improve the signal to noise ratio.

Spectral manipulation such as baseline correction/adjustment and smoothing were performed using the Spectracalc software package GRAMS (Galactic Industries Corporation, NH, USA). Band component analysis was undertaken using the Jandel 'Peakfit' software package that enabled the type of fitting function to be selected and allows specific parameters to be fixed or varied accordingly. Band fitting was done using a Lorentzian-Gaussian cross-product function with the minimum number of component bands used for the fitting process. The Gaussian-Lorentzian ratio was maintained at values greater than 0.7 and fitting was undertaken until reproducible results were obtained with squared correlations of $r^{2}$ greater than 0.995 .

\section{Results and discussion}

\subsection{Chemical characterization}

The SEM image of olmiite sample studied in this work is shown in Fig. 1. The image shows a olmiite crystal aggregate. The mineral occurs in association with small amounts of manganese oxides. Qualitative chemical analysis shows a Ca and Mn silicate (Fig. 2). No other elements were detected (see Table 1).

\subsubsection{Thermogravimetric analysis}

The thermogravimetric analysis of olmiite is recorded in Fig. 3. A mass loss of $8.8 \%$ is observed at $502{ }^{\circ} \mathrm{C}$. The theoretical mass loss based upon the formula $\mathrm{CaMn}\left[\mathrm{SiO}_{3}(\mathrm{OH})\right](\mathrm{OH})$ is $8.737 \%$. The temperature range for this mass loss is very narrow. The following

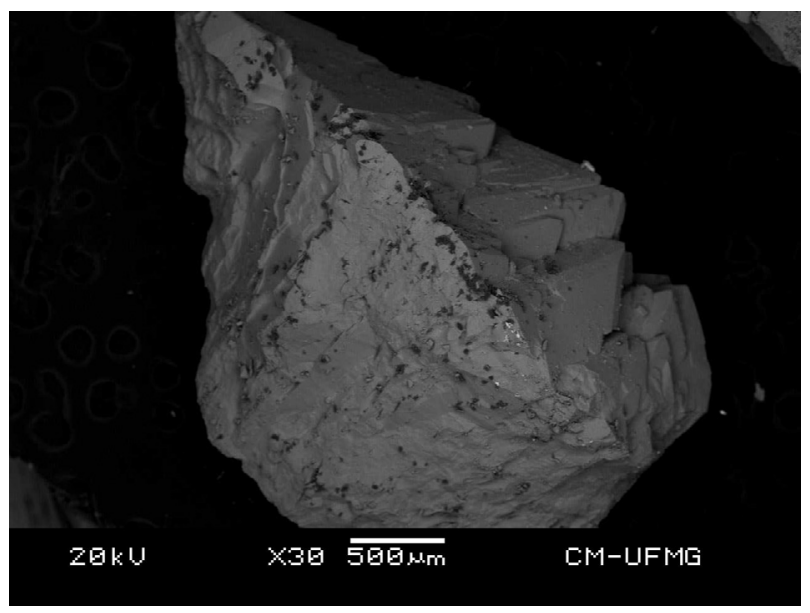

Fig. 1. Backscattered electron image (BSI) of an olmiite crystal aggregate up to $3.0 \mathrm{~mm}$ in length. 


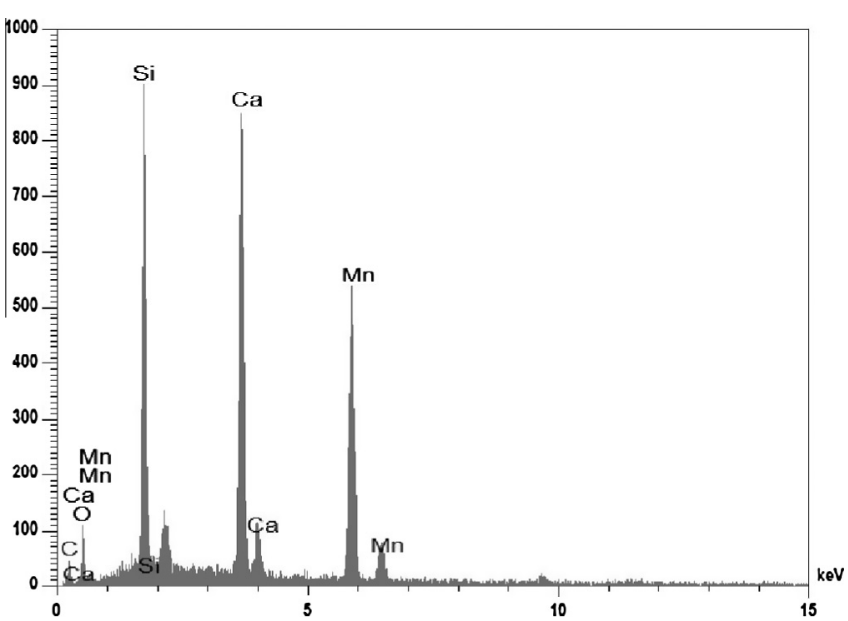

Fig. 2. EDS analysis of olmiite.

Table 1

Chemical analysis of olmiite.

\begin{tabular}{lrll}
\hline Constituent & wt.\% & Number of atoms & Probe standard/crystal \\
\hline $\mathrm{SiO}_{2}$ & 30.39 & 1.03 & Quartz \\
$\mathrm{CaO}$ & 32.63 & 1.19 & Anortite \\
$\mathrm{MnO}$ & 27.74 & 0.77 & Rodhonite \\
$\mathrm{MgO}$ & 0.01 & 0.00 & MgO \\
$\mathrm{FeO}$ & 0.04 & 0.01 & Siderite \\
$\mathrm{H}_{2} \mathrm{O}$ & 8.87 & 1.96 & Stoichimetry \\
Total & 99.02 & 4.96 & \\
\hline
\end{tabular}

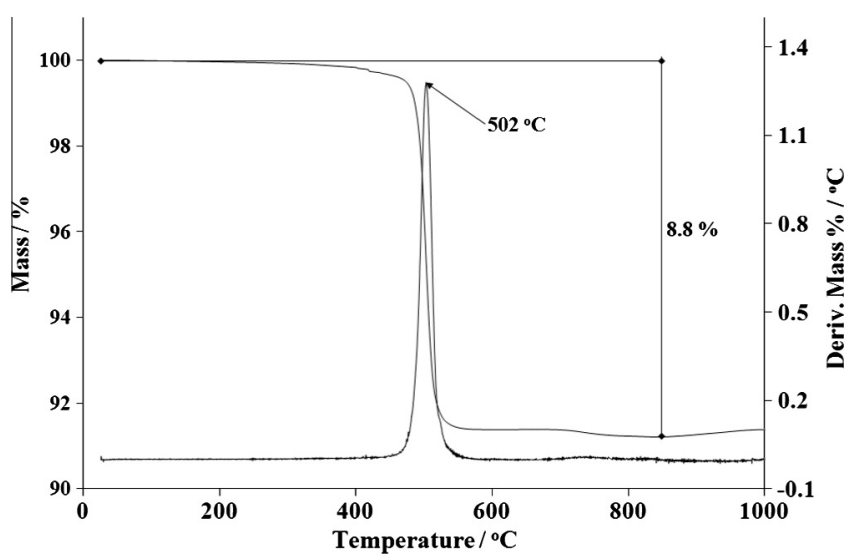

Fig. 3. Thermogravimetric and derivative thermogravimetric analysis of olmiite.

chemical reaction is proposed for the thermal decomposition of olmiite:

$\mathrm{CaMn}\left[\mathrm{SiO}_{3}(\mathrm{OH})\right](\mathrm{OH}) \rightarrow \mathrm{CaMnSiO}_{4}+\mathrm{H}_{2} \mathrm{O}$

\subsection{Vibrational spectroscopy}

The Raman spectrum of olmiite over the $100-4000 \mathrm{~cm}^{-1}$ spectral range is illustrated in Fig. 4a. This figure shows the position and relative intensity of the Raman bands. It is noted that there are large parts of the spectrum where no intensity is found; therefore, the Raman spectrum is subdivided into sections depending upon the type of vibration being analyzed. The infrared spectrum of olmiite over the $500-4000 \mathrm{~cm}^{-1}$ spectral range is displayed in Fig. 4b. This figure shows the position and relative intensity of

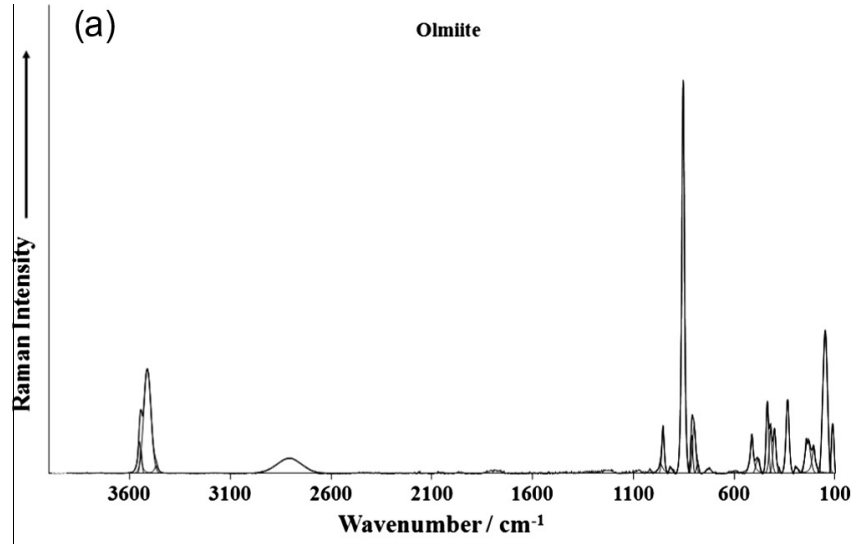

(b)

Olmiite

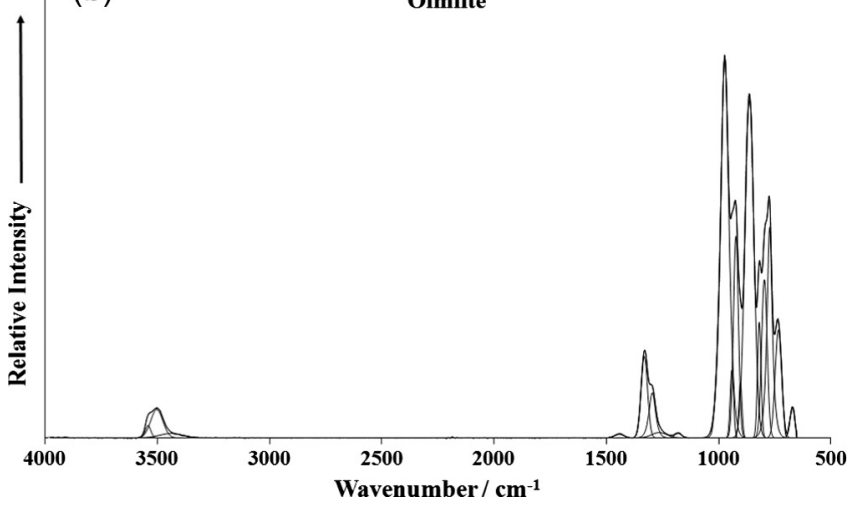

Fig. 4. (a) Raman spectrum of olmiite over the $4000-100 \mathrm{~cm}^{-1}$ spectral range and (b) Infrared spectrum of olmiite over the $4000-500 \mathrm{~cm}^{-1}$ spectral range.

the infrared bands. Again, there are large parts of the infrared spectrum where little or no intensity is observed and therefore, the spectrum is subdivided into sections based upon the type of vibration being studied.

The Raman spectrum of olmiite over the $700-1000 \mathrm{~cm}^{-1} \mathrm{spec}-$ tral range is shown in Fig. 5a. The Raman spectrum is dominated by an intense peak at $853 \mathrm{~cm}^{-1}$. Dowty showed that the $-\mathrm{SiO}_{3}$ units had a unique band position of $980 \mathrm{~cm}^{-1}$ [3] (see Figs. 2 and 4 of this reference). Dowty also showed that $\mathrm{Si}_{2} \mathrm{O}_{5}$ units had a Raman peak at around $1100 \mathrm{~cm}^{-1}$. Olmiite consists of isolated $\mathrm{SiO}_{3}(-$ $\mathrm{OH})$ tetrahedra continuously connected along the [100] direction to two $\mathrm{M}_{2} \mathrm{O}_{7}$ polyhedra by sharing edges. The $\mathrm{M} 2-\mathrm{Si}$ chains are linked together by corner sharing to form waved sheets parallel to $(010)$ Alternating sheets are linked together by M1 octahedra and hydrogen bonds, resulting in a strongly bonded polyhedral network [1,2]. Thus, the Raman peak at $853 \mathrm{~cm}^{-1}$ is assigned to the $\mathrm{SiO}$ stretching vibration of the $\mathrm{SiO}_{3}(\mathrm{OH})$ units. The two bands at 914 and $953 \mathrm{~cm}^{-1}$ with a low intensity shoulder at $964 \mathrm{~cm}^{-1}$ are attributed to the antisymmetric vibrations of the $\mathrm{SiO}_{3}(\mathrm{OH})$ units. The two Raman bands at 799 and $811 \mathrm{~cm}^{-1}$ are attributed to the $\mathrm{SiOH}$ deformation modes.

The infrared spectrum of olmiite over the $600-1100 \mathrm{~cm}^{-1} \mathrm{spec}$ tral range is shown in Fig. 5b. Strong infrared bands are observed at 860 and $970 \mathrm{~cm}^{-1}$. This latter band together with the infrared bands at 900,920 and $938 \mathrm{~cm}^{-1}$ are assigned to the $\mathrm{SiO}$ antisymmetric stretching vibration. The infrared band at $860 \mathrm{~cm}^{-1}$ is ascribed to the SiO symmetric stretching band. Other infrared bands are observed at $668,731,769,793$ and $816 \mathrm{~cm}^{-1}$. If we follow the assignment of the Raman bands then these bands are due to hydroxyl deformation modes. 


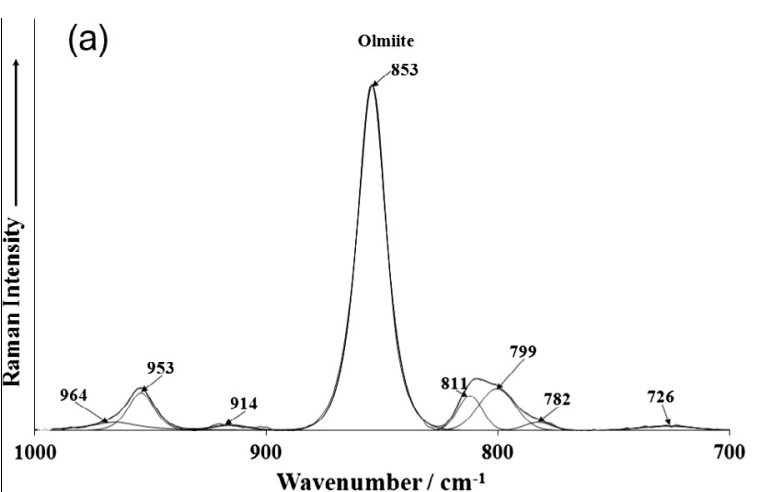

(b)

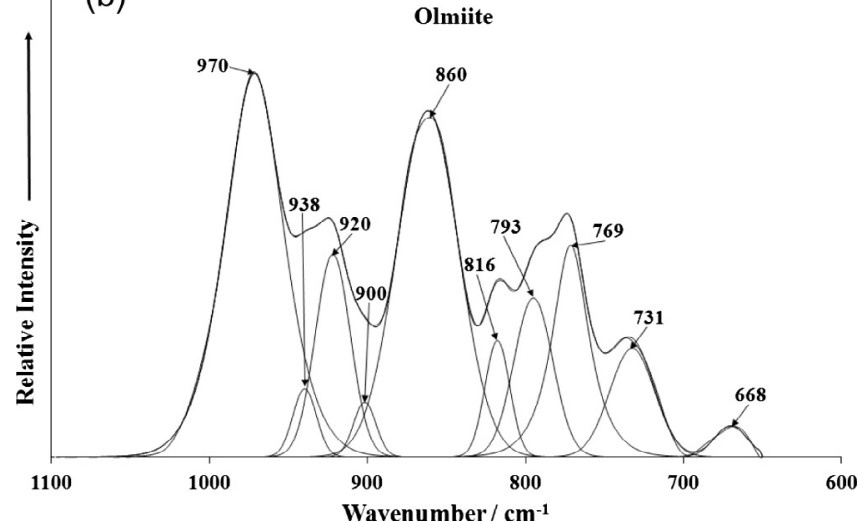

Fig. 5. (a) Raman spectrum of olmiite over the $1000-700 \mathrm{~cm}^{-1}$ spectral range and (b) Infrared spectrum of olmiite over the $1100-600 \mathrm{~cm}^{-1}$ spectral range.

(a)

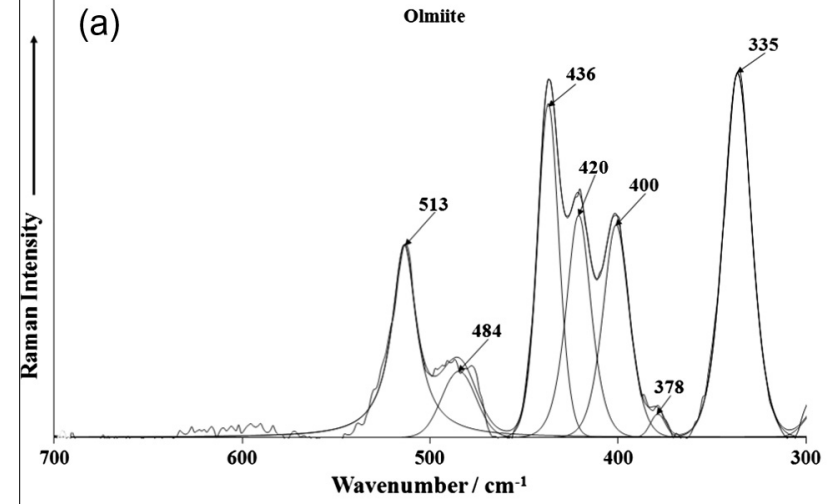

(b)

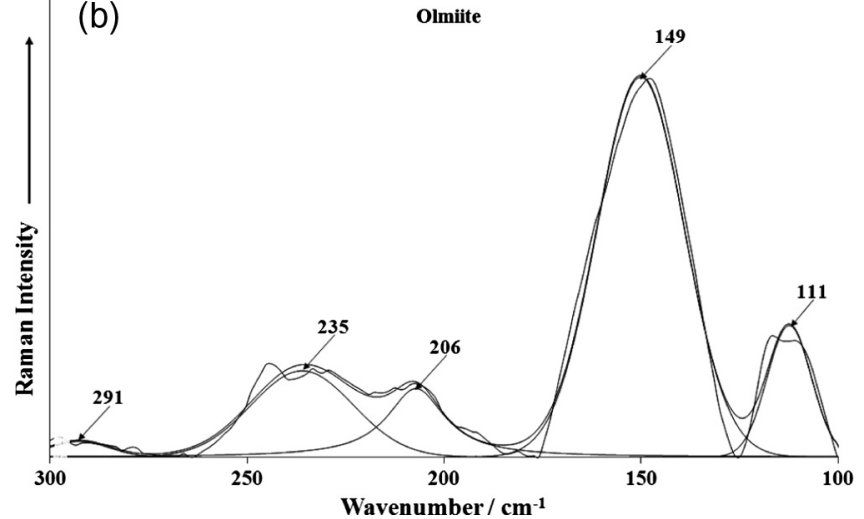

Fig. 6. (a) Raman spectrum of olmiite over the $700-300 \mathrm{~cm}^{-1}$ spectral range and (b) Raman spectrum of olmiite over the $300-100 \mathrm{~cm}^{-1}$ spectral range.
The Raman spectra over the $300-700 \mathrm{~cm}^{-1}$ spectral range and over the $100-300 \mathrm{~cm}^{-1}$ spectral range are presented in Fig. 6. Raman bands are noted at (a) 484 and $513 \mathrm{~cm}^{-1}$, (b) 400,420 and $436 \mathrm{~cm}^{-1}$ and (c) at $335 \mathrm{~cm}^{-1}$. The first two sets of bands are assigned to OSiO bending modes. The band at $335 \mathrm{~cm}^{-1}$ is assigned to $\mathrm{CaO}$ stretching vibrations. Dowty calculated the band position of these bending modes for different siloxane units [3]. Dowty demonstrated the band position of the bending modes for $\mathrm{SiO}_{3}$ units at around $650 \mathrm{~cm}^{-1}$. This calculated value is in harmony with the higher wavenumber band observed at $663 \mathrm{~cm}^{-1}$. According to Adams et al. [4] the band at $432 \mathrm{~cm}^{-1}$ is due to the coincidence of both the $B_{2 g}$ and $E_{g}$ modes. Raman bands are observed in the

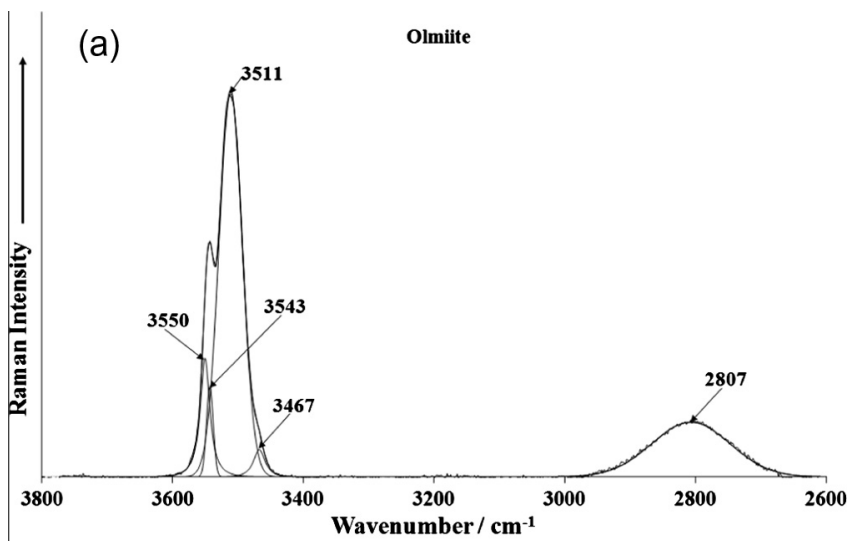

(b)

Olmiite

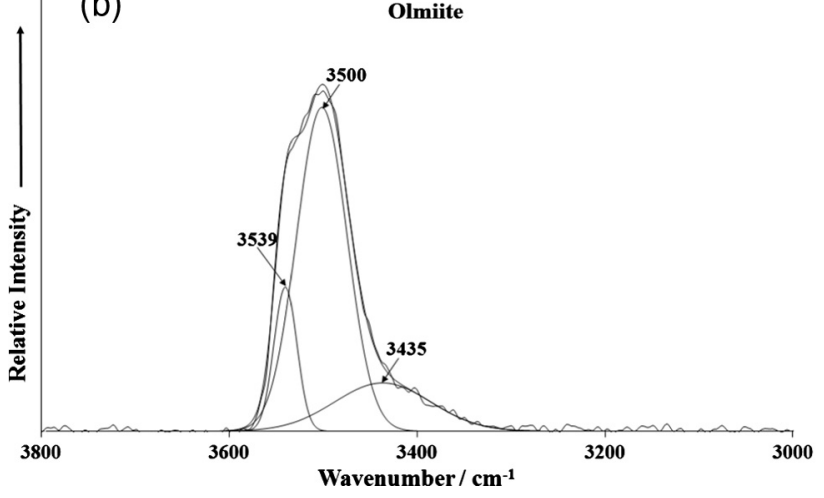

Fig. 7. (a) Raman spectrum of olmiite over the $3800-2600 \mathrm{~cm}^{-1}$ spectral range and (b) Infrared spectrum of olmiite over the $3800-3000 \mathrm{~cm}^{-1}$ spectral range.

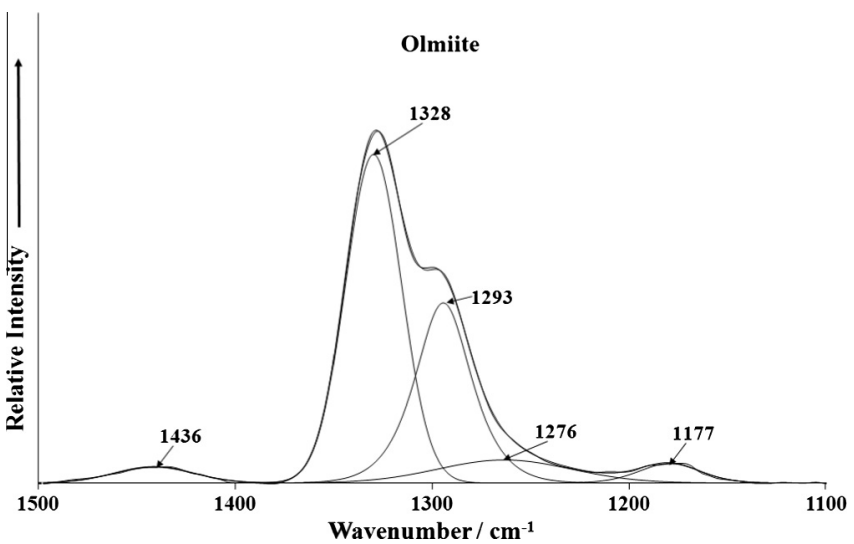

Fig. 8. Infrared spectrum of olmiite (lower spectrum) in the $1500-1100 \mathrm{~cm}^{-1}$ spectral range. 
far low wavenumber region at 111, 149, 296, 235 and $291 \mathrm{~cm}^{-1}$. These bands are simply described as lattice vibrations.

The Raman spectrum of olmiite over the $2600-3800 \mathrm{~cm}^{-1} \mathrm{spec}-$ tral range is reported in Fig. 7a. Two prominent peaks are observed at 3511 and $3550 \mathrm{~cm}^{-1}$. These bands are assigned to the $\mathrm{OH}$ stretching vibration of the $\mathrm{SiO}_{3}(\mathrm{OH})$ units. The observation of multiple bands proves that the $\mathrm{OHs}$ are not equivalent in the olmiite structure. The infrared spectrum of olmiite over the 3000$3800 \mathrm{~cm}^{-1}$ spectral range is shown in Fig. $7 \mathrm{~b}$. Infrared bands are found at 3500 and $3539 \mathrm{~cm}^{-1}$ with a broad shoulder at $3435 \mathrm{~cm}^{-1}$. The infrared bands support the concept of the nonequivalence of the $\mathrm{OH}$ units in the olmiite structure. The broad feature may be ascribed to water stretching modes; however, no water bending mode was observed in the infrared spectrum in the $1500-1800 \mathrm{~cm}^{-1}$ spectral range. Some infrared bands were observed in the 1100 to $1500 \mathrm{~cm}^{-1}$ spectral range (Fig. 8). Two infrared bands are observed at 1293 and $1328 \mathrm{~cm}^{-1}$ with lower intensity bands observed at 1177, 1276 and $1436 \mathrm{~cm}^{-1}$. These bands are all related to $\mathrm{SiO}$ vibrations.

\section{Conclusions}

We have studied the mineral olmiite $\mathrm{CaMn}\left[\mathrm{SiO}_{3}(\mathrm{OH})\right](\mathrm{OH})$ which forms a continuous series with its calcium analogue poldervaartite $\mathrm{CaCa}\left[\mathrm{SiO}_{3}(\mathrm{OH})\right](\mathrm{OH})$ using a combination of electron microscopy with EDX analysis, thermogravimetric analysis, infrared and Raman spectroscopy. This mineral occurs as a product of hydrothermal alteration of primary sedimentary and low-grade metamorphic ores in a temperature range from $250{ }^{\circ} \mathrm{C}$ to $400{ }^{\circ} \mathrm{C}$. These temperatures are well below the thermal decomposition of olmiite of $502{ }^{\circ} \mathrm{C}$.
Raman spectroscopy identifies a peak at $853 \mathrm{~cm}^{-1}$ assigned to the $\mathrm{SiO}$ stretching vibration of the $\mathrm{SiO}_{3}(\mathrm{OH})$ units. Strong infrared bands observed at 860 and $970 \mathrm{~cm}^{-1}$ are assigned to this vibration. Two prominent Raman peaks observed at 3511 and $3550 \mathrm{~cm}^{-1}$ are assigned to the $\mathrm{OH}$ stretching vibration of the $\mathrm{SiO}_{3}(\mathrm{OH})$ units. The equivalent infrared bands found at 3500 and $3539 \mathrm{~cm}^{-1}$ supports the concept of the non-equivalence of the $\mathrm{OH}$ units in the olmiite structure. Vibrational spectroscopy enables a detailed assessment of the molecular structure of olmiite to be attained.

\section{Acknowledgments}

The financial and infra-structure support of the Discipline of Nanotechnology and Molecular Science, Science and Engineering Faculty of the Queensland University of Technology, is gratefully acknowledged. The Australian Research Council (ARC) is thanked for funding the instrumentation. The authors would like to acknowledge the Center of Microscopy at the Universidade Federal de Minas Gerais (http://www.microscopia.ufmg.br) for providing the equipment and technical support for experiments involving electron microscopy. R. Scholz thanks to CNPq - Conselho Nacional de Desenvolvimento Científico e Tecnológico (Grant No. 306287/ 2012-9). Ž. Žigovečki Gobac thanks to Ministry of Science, Education and Sports of the Republic of Croatia, under Grant No. 1190000000-1158.

\section{References}

[1] R. Pagano, A. Guastoni, F. Pezzotta, Min. Rec. 39 (2008) 373-381.

[2] Y. Dai, G.E. Harlow, A.R. McGhie, Am. Min. 78 (1993) 1082-1087.

[3] E. Dowty, Phys. Chem. Min. 14 (1987) 80-93.

[4] D.M. Adams, R.S. Armstrong, S.P. Best, Inorg. Chem. 20 (1981) 1771-1776. 